\title{
Comparative genomics of an endophytic Pseudomonas putida isolated from mango orchard
}

\author{
Huma Asif ${ }^{1}$, David J. Studholme ${ }^{2}$, Asifullah Khan ${ }^{1 \#}$, M. Aurongzeb ${ }^{1}$, Ishtiaq A. Khan ${ }^{1}$ and M. Kamran \\ Azim $^{1}$ \\ ${ }^{1}$ Jamil-ur-Rahman Center for Genome Research, Dr. Panjwani Center for Molecular Medicine and Drug \\ Research, International Center for Chemical and Biological Sciences, University of Karachi, Karachi, \\ Pakistan. \\ ${ }^{2}$ Biosciences, University of Exeter, Exeter, U.K.
}

\begin{abstract}
We analyzed the genome sequence of an endophytic bacterial strain Pseudomonas putida TJI51 isolated from mango bark tissues. Next generation DNA sequencing and short read de novo assembly generated the 5,805,096 bp draft genome of $P$. putida TJI51. Out of 6,036 protein coding genes in $P$. putida TJI51 sequences, 4,367 (72\%) were annotated with functional specifications, while the remaining encoded hypothetical proteins. Comparative genome sequence analysis revealed that the $P$. putida TJI51genome contains several regions, not identified in so far sequenced $P$. putida genomes. Some of these regions were predicted to encode enzymes, including acetylornithine deacetylase, betaine aldehyde dehydrogenase, aldehyde dehydrogenase, benzoylformate decarboxylase, hydroxyacylglutathione hydrolase, and uroporphyrinogen decarboxylase. The genome of $P$. putida TJI51 contained three nonribosomal peptide synthetase gene clusters. Genome sequence analysis of $P$. putidaTJI51 identified this bacterium as an endophytic resident. The endophytic fitness might be linked with alginate, which facilitates bacterial colonization in plant tissues. Genome sequence analysis shed light on the presence of a diverse spectrum of metabolic activities and adaptation of this isolate to various niches.
\end{abstract}

Keywords: Mangifera indica; bacterial genomics; plant-associated bacteria; endophyte.

Received: July 27, 2015; Accepted: December 20, 2015.

\section{Introduction}

The genus Pseudomonas is a versatile and ecologically important group of bacteria. They are Gram-negative, slightly curved flagellated rods and prolific colonizers of surfaces (Clarke, 1982). Pseudomonas species have been isolated from diverse ecosystems including marine, freshwater and terrestrial environment including plants and animals sources (Achouak et al., 2000; Manaia and Moore, 2002; Liu et al., 2008). This widespread distribution is due to physiological and genetic diversity (Spiers et al., 2000). For instance, an attempt to differentiate $P$. Stutzeri populations from a variety of ecological niches resulted in several distinguishable genomovars (Rossello et al., 1991). Comparative genomics of the Pseudomonas strains revealed

Send correspondence to M. Kamran Azim, International Center for Chemical and Biological Sciences, University of Karachi, Karachi-75270, Pakistan. Email: kamran.azim@iccs.edu \& mkamranazim@yahoo.co.uk

Present addresses: ${ }^{\circledR}$ Department of Microbiology, Institute of Biomedical Sciences, University of Sao Paulo, Sao Paulo, SP, Brazil. "Department of Biochemistry,Abdul Wali Khan University, Mardan-23200, Pakistan. much variability in their genome sizes, ranging from 3.7 Mbp for Pseudomonas stutzeri to $7.1 \mathrm{Mbp}$ for Pseudomonas aeruginosa (Schmidt et al., 1996; Ginard et al., 1997).

Pseudomonas putida, an important member of genus Pseudomonas, is frequently found in temperate waters and diverse soil environments. It is renowned for its ability to degrade a wide variety of natural and man-made compounds, and thus plays an important role in maintaining environmental quality (Dejonghe et al., 2001). Available complete or draft genome sequences of several $P$. putida isolates from different parts of the world provided a rich and diverse 'meta-dataset' (Genome OnLine Database; www.genomeonline.org). Pseudomonas putida KT2440 isolated in Japan is so far, the best characterized strain, which is a plasmid free derivative of Pseudomonas putidamt-2 (Timmis, 2002). Other strains with sequenced genomes include Pseudomonas putida W619, a plant growth-promoting endophytic bacterium, Pseudomonas putida $\mathrm{F} 1$, the aromatic hydrocarbon degrading bacterium, and Pseudomonas putida GB-1, a robust manganese $\left(\mathrm{Mn}^{2+}\right)$ oxidizer. Pseudomonas putida W619 and Pseudomonas 
putida KT2440 have been found in association with plants (Wu et al., 2011). However, genome sequences representing more $P$. putida strains are required to better determine the prevailing diversity and stratification patterns of this environmentally important bacterium. Here, we report the draft genome sequence of Pseudomonas putida TJI51 isolated from infected mango bark. The comparative sequence analysis revealed several genomic loci specific to this endophytic Pseudomonas putida isolate.

\section{Material and Methods}

\section{Isolation and bacteriological characterization of Pseudomonas putida TJI51}

Isolation of Pseudomonas putida TJI51 has been described elsewhere (Khan et al., 2014). Briefly, Pseudomonas putida TJI51 was isolated from bark of a mango tree situated in the Horticultural Garden, Sindh Agriculture University, Tando Jam, Pakistan. The bark sample $(100 \mathrm{mg})$ was surface sterilized using $1.3 \%$ sodium hypochlorite solution, followed by homogenization using sea sand and $0.8 \% \mathrm{NaCl}$. The homogenate was incubated on LB plates and isolated colonies were characterized further. Colony PCR of isolated bacterial colonies was performed according to Khan et al. (2014) for amplification of $16 \mathrm{~S}$ ribosomal DNA. Sanger sequencing of PCR products was carried out, followed by BLASTN analysis (Altschulet al., 1990) of resulted sequences against the NCBI 16S ribosomal RNA sequence (Bacteria and Archaea) database.

Bacteriological analysis was done using a standard protocol for Pseudomonas identification, including sulphur, indole, citrate, motility, urease, and TSI agar tests. Tests for lactose and glucose fermentation, PSP (Pseudomonas agar Pyocyanin) and PSF (Pseudomonas agar Flourescein) were also carried out (Murray et al., 2007). Antibiotic susceptibility tests were carried out using disc diffusion method with the following antibiotics discs (Oxoid Ltd. England): Ceftriaxone $(30 \mu \mathrm{g})$, Cefixime $(5 \mathrm{mg})$ and Ceftazidime $(30 \mu \mathrm{g})$ (3rd-generation cephalosporins); Cefuroxime $(30 \mu \mathrm{g})$ (2nd generation cephalosporin); Ciprofloxacin (5 $\mu \mathrm{g})$ (Quinolone); Sulfamethoxazole $(25 \mu \mathrm{g})$ (Sulfonamide); Polymyxin B (300 units) (Polypeptides); Meropenem (10 $\mu \mathrm{g})$, Imipenem $(10 \mu \mathrm{g})$ (Carbapenems); Tetracycline $(30 \mu \mathrm{g})$ (Tetracyclines); Amoxicillin/clavulanate $(30 \mu \mathrm{g})$, Tazobactam $(110 \mu \mathrm{g})$ (Penicillin combinations); Gentamicin $(10 \mu \mathrm{g})$, Amikacin $(30 \mu \mathrm{g})$ (Aminoglycosides); Aztreonam $(30 \mu \mathrm{g})$ (Monobactams) and Chloramphenicol $(30 \mu \mathrm{g})$. Bacterial isolates were also inoculated on casein agar and blood agar (Blood agar base, Oxoid code CM 271) for determination of proteolytic and haemolytic activities.

\section{Genome sequencing and data analysis}

Genomic DNA $(5 \mu \mathrm{g})$ was purified from an overnight culture of $P$. putida TJI51 using a bacterial genomic DNA isolation kit (Bio Basic Inc.) and subjected to Illumina next generation sequencing. A paired-end library of insert size $500 \mathrm{bp}$ was prepared according to the manufacturer's protocol followed by HiSeq2000 system sequencing (Illumina Inc., San Diego, USA). The obtained raw sequence data was subjected to filtering of low quality score reads (i.e. $<$ Q20) using the FastX toolkit (http://hannonlab.cshl.edu/fastx toolkit/). CLC Genomics Workbench version 7.5.2 was used for denovo paired-end sequence assembly. The annotation of the assembled genome sequences was carried out using the NCBI Prokaryotic Genomes Automatic Annotation Pipeline (PGAAP) (http://www.ncbi.nlm.nih.gov/ genomes/static/Pipeline.html).

\section{Comparative genome analysis}

We used MUMMER (Delcher et al., 1999) to align assembled contigs with several Pseudomonas genome sequences. A molecular phylogeny analysis of $P$. putida TJ151 was carried out with several housekeeping gene sequences and multi-locus sequence analysis (MLSA) using MEGA version 4.0 (neighbor-joining method) (Saitou and Nei, 1987). The comparative analyses with available bacterial genome sequences were performed using BLAST programs (BLASTN, TBLASTX and BLASTP) (Altschulet al., 1990). The comparative genomics analysis of $P$. putida TJ151 was carried out with Pseudomonas putida KT2440 (NC_002947), Pseudomonas putida GB-1 (NC_010322), Pseudomonas putida w619 (NC_010501), Pseudomonas putida F1 (NC_009512), Pseudomonas fluorescens Pf5 (NC_004129), Pseudomonas syringae pv. Tomato DC3000 (NC_004578), Pseudomonas syringae pv. Phaseolicola 1448A (NC 005773), Pseudomonas entomophila L48 (NC_008027), Pseudomonas aeruginosa UCBPP-PA14 (NC_008463), Pseudomonas aeruginosa PA7 (NC_009656), Pseudomonas aeruginosa LESB58 (NC 011770), Pseudomonas fluorescens SBW25 (NC 012660) and Pseudomonas fluorescens Pf01 (NC_007492) using SEED viewer (Dejongh et al., 2007). ClustalX version 2.0 (Larkin et al., 2007) and MEGA4 software (Tamura et al., 2007) were used for multiple sequence alignment and phylogenetic tree construction respectively.

A comparison of genomic DNA $\mathrm{G}+\mathrm{C}$ content between P. putida TJ151 and other Pseudomonas strains was done using the Integrated Microbial Genomes (IMG) system (Markowitz et al., 2010). The sequence analysis of biosynthetic gene clusters for bacterial secondary metabolites was carried out by antiSMASH 2.0 web server (Blin et al., 2013). The association of metabolic pathways with the annotated protein sequences was studied using the KEGG server (Kanehisa et al., 2008). 


\section{Results}

We isolated a number of endophytic Pseudomonas strains from dead tissues of bark, leaves and inflorescence of mango (Mangifera indica) trees grown in agricultural farms in mango growing districts in Sindh province of $\mathrm{Pa}$ kistan (Khan et al., 2014). The bacterial characterization was carried out by standard procedures and $16 \mathrm{~S}$ ribosomal DNA sequencing, which identified isolate-number TJI51 as Pseudomonas species. Antibiotics susceptibility assays of Pseudomonas sp.TJI51 showed resistance against Ampicilin, Cefixime ( $3^{\text {rd }}$ generation cephalosporin) and Sulfamethoxazole (Sulfonamide). Pseudomonas sp. TJI51 was found to be oxidase and citrate positive; nonhemolytic, nonproteolytic, a non-lactose fermenter and motile. Genome-wide DNA sequencing and comparative genomics were done for detailed functional characterization of this isolate.

\section{Genome sequence of Pseudomonas putida TJI51}

The sequencing of chromosomal and plasmid DNA of Pseudomonas sp. TJI51 resulted in 651 mega bases (Mb) of raw data with read length of $90 \mathrm{bp}$. During raw data filtering by the FASTX-Toolkit, low quality bases $(\leq \mathrm{Q} 20$ bases) at 3 ends of the sequence reads, adaptor sequences and reads containing Ns (undetermined/ambiguous nucleotides) were removed. Accordingly, 5,777,778 reads of 90 bp length were obtained (total nucleotides $=520,000,020$ ). De novo assembly of sequence reads using CLC Genomics Workbench resulted in 208 contigs of $\geq 541$ bp length. Total sequence length of the assembly was 5,805,096 bp, which was in accordance with the previously reported 6.1 Mb genome of P. Putida (Nelson et al., 2002; Moon et al., 2008; Peixet al., 2009). The $\mathrm{N}_{50}$ of assembly was 53,388 bp and the length of the longest contig was 240,918bp. The depth of coverage was estimated as $89 \mathrm{X}$, and mean $\mathrm{G}+\mathrm{C}$ content was $62 \%$ (Table 1 ). The $\mathrm{G}+\mathrm{C}$ content distribution plot showed that most of the scaffolds had the GC content in the range of $58-64 \%$, which is in agreement with other Pseudomonas strains. The master record for the genome

Table 1 - Sequencing and assembly data of $P$. putida TJ151 genome.

\begin{tabular}{lc}
\hline Library characteristics & Data \\
\hline No. of filtered paired-end reads & $5,777,778$ \\
Read length & 90 \\
No. of filtered nucleotide bases & $520,000,020$ \\
Number of assembled contigs & 208 \\
Length of longest contigs (nucleo- & 240,918 \\
tides) & \\
Total length of contigs (nucleo- & $5,805,096$ \\
tides) & \\
N50 of contigs (nucleotides) & 53,388 \\
Fold coverage & $89 \mathrm{X}$ \\
\hline
\end{tabular}

shotgun sequencing project of $P$. species TJI51 can be accessed under GenBank under accession number AEWE00000000.2.

\section{Comparative genomics of Pseudomonas sp. TJ151}

The 208 scaffolds of the Pseudomonas sp. TJ151 genome sequence were aligned with 13 Pseudomonas genomic sequences using MUMMER (Delcher et al., 1999). The analysis showed that $P$. putida sequences aligned with greater proportion to $P$. sp. TJI51 sequences (Table 2). The highest percentages of aligned nucleotides were for $P$. putida GB-1, F1 and KT2440 (Figure 1). The genome-wide alignment showed that $33-35 \%$ of the $P$. sp. TJ1-51 sequences were aligned with $P$. putida GB-1, P. putida F1, and $P$. putida KT2440; $21 \%$ with Pseudomonas putida W619 genome; $19 \%$ with $P$. entomophila, while $2-4.5 \%$ with Pseudomonas syringae, $P$. fluorescens, and $P$. aeruginosa genomic sequences. Hence, these alignments identified $P$. sp. TJI51 as being more similar to P. Putida than to the other species included in this analysis.

Further support regarding the classification of $P$. sp. TJI51 as P. Putida was obtained from phylogenetic studies. DNA sequences of five conserved housekeeping genes, $g y r B$, lepA, recA, recG and $r p o D$, were selected for the phylogenetic analysis of $P$. sp. TJ151 (Santos and Ochman, 2004). The corresponding gene sequences of 13 Pseudomonas strains selected on the basis of BLAST results were retrieved from GenBank (Table 2) (Madden et al., 1996). In the resultant phylogenetic tree, $P$. sp. TJ151 grouped with $P$. putida GB-1 and $P$. putida w619, with boot strap support values of 97 and $100 \%$ respectively (Figure 2A). Moreover, a phylogenetic analysis based on the concatenated amino acid sequence data of ten orthologous conserved proteins was also carried out. These universally distributed bacterial genes included transfer RNA synthetases, translation elongation factor, and DNA-directed RNA polymerase beta subunit (Brown et al., 2001). Amino acid sequence alignment of these genes was made using the NJ method. This analysis also showed the alliance of $P$. sp. TJ151 with $P$. putida GB-1 and $P$. putida w619, with bootstrap support values 97 and 100\% respectively (Figure 2B). The graphical representation of genome-wide sequence alignment indicated that $P$. putida TJ151 sequences covered most of the genome map of $P$. putida GB-1 and $P$. putida F1 with several gap regions (Figure 1).

\section{Annotation of Pseudomonas putida TJ151 genome}

The NCBI Prokaryotic Genome Annotation Pipeline (PGAAP) annotated 6,036 protein coding genes in $P$. putida TJI51 sequences. In total, $72 \%$ of protein coding genes $(4,367)$ were annotated with functional specifications, while the remaining werehypothetical proteins $(1,669)$. The distribution of these genes in different bacterial subsystems is shown in Figure 3. Gene ontology by PGAAP identified protein coding genes involved in core 
Table 2 - Genome-wide pair-wise sequence alignment of $P$. putida TJ151 with 13 Pseudomonas species.

\begin{tabular}{|c|c|c|c|c|c|}
\hline \multirow[t]{2}{*}{ Pseudomonas genomes } & GenBank & Genome size & $\begin{array}{l}\text { Pseudomonas putida TJI51 } \\
\text { nucleotides aligned }\end{array}$ & $\begin{array}{c}\text { Genome } \\
\text { coverage }(\%)\end{array}$ & $\begin{array}{c}\text { GC content } \\
(\%)\end{array}$ \\
\hline & \multicolumn{5}{|l|}{ accession number } \\
\hline Pseudomonas putida $\mathrm{KT} 2440$ & NC_002947 & 6181861 & 2068300 & 33.457 & 62 \\
\hline Pseudomonas putida GB-1 & NC_010322 & 6078430 & 2152707 & 35.415 & 62 \\
\hline Pseudomonas putida F1 & NC_009512 & 5959964 & 1987103 & 33.340 & 62 \\
\hline Pseudomonas putida $\mathrm{w} 619$ & NC_010501 & 5774330 & 1259208 & 21.806 & 61 \\
\hline Pseudomonas entomophilaL48 & NC_008027 & 5888632 & 1121068 & 19.037 & 64 \\
\hline Pseudomonas fluorescensPf5 & NC_004129 & 7072643 & 311819 & 4.408 & 61 \\
\hline Pseudomonassyringaepv. tomatostr. DC 3000 & NC_004578 & 6386667 & 117603 & 1.841 & 58 \\
\hline Pseudomonassyringaepv. phaseolicola1448A & NC_005773 & 5917006 & 113979 & 1.926 & 58 \\
\hline Pseudomonas aeruginosa UCBPP-PA14 & NC_008463 & 6523118 & 144831 & 2.220 & 66 \\
\hline Pseudomonas aeruginosa PA7 & NC_009656 & 6576011 & 163735 & 2.489 & 66 \\
\hline Pseudomonas aeruginosa LESB58 & NC_011770 & 6054647 & 18562 & 0.306 & 66 \\
\hline Pseudomonas fluorescensSBW25 & NC_012660 & 6720050 & 216725 & 3.225 & 60 \\
\hline Pseudomonas fluorescensPf01 & NC_007492 & 6436448 & 256766 & 3.989 & 61 \\
\hline
\end{tabular}
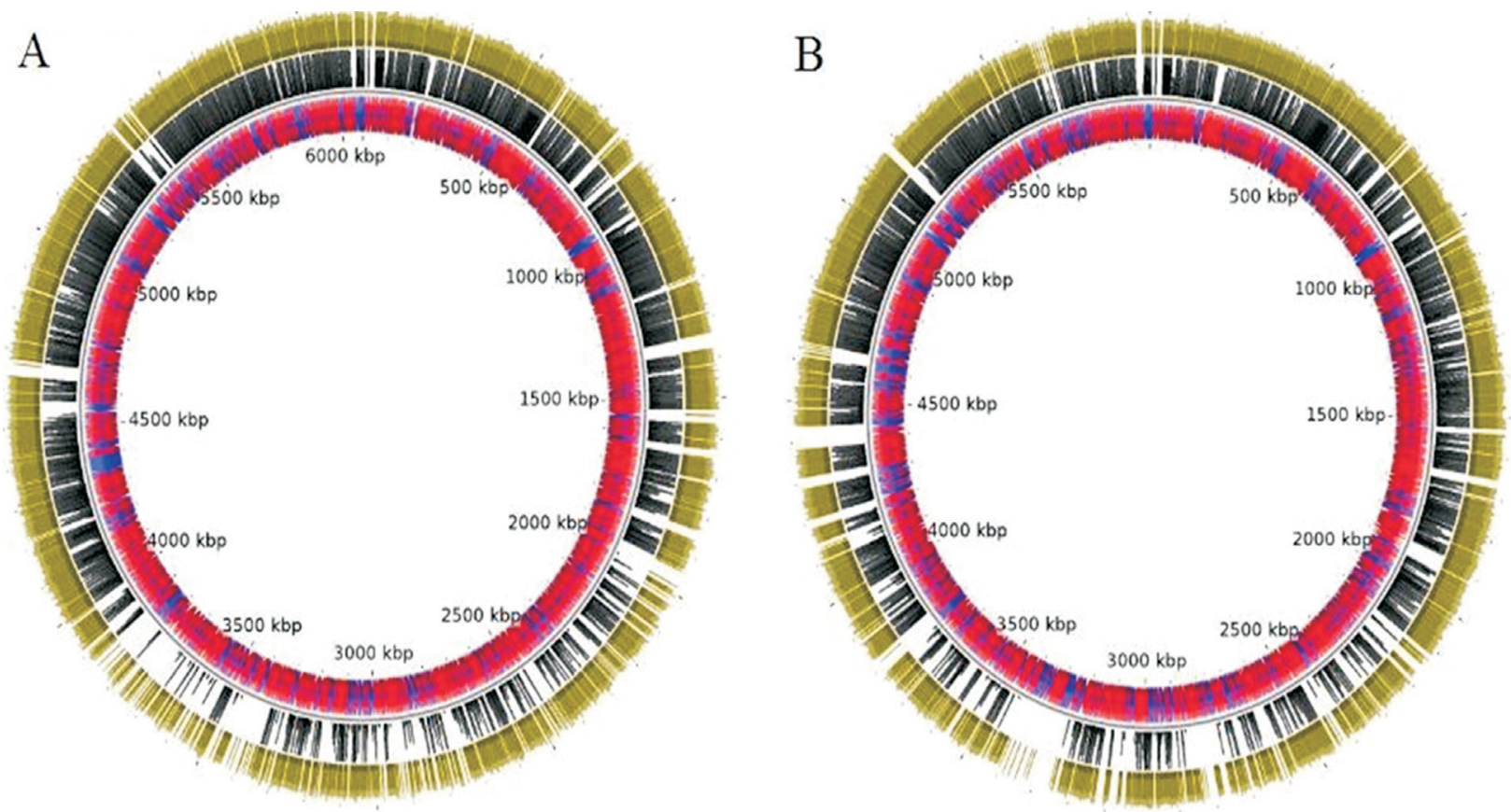

Predicted genes (-strand)

Predicted genes (+ strand)
Depth of coverage by Illumina reads

Similarity to Velvet de novo assembly

Figure 1 - Diagrammatic representation of MUMMER (Delcheret al., 1999) generated genome-wide alignments of $P$. putida TJI51 contigs with genome sequences of $P$. putida $\mathrm{GB}-1$ (A) and P. putida F1 (B).

and accessory functions. Genes involved in core functions included nucleic acid biosynthesis, amino acid metabolism, carbohydrate metabolism, protein metabolism, cell wall and capsule synthesis, respiration, etc. A significant number of genes encoding accessory functions were also found, including iron acquisition, metabolism of aromatic compounds, stress response motility and chemotaxis.

\section{Discussion}

We characterized the genome of an endophytic $P$. putida strain isolated from mango tree located in an agricultural farm in Sindh province of Pakistan. Genome insight provided information regarding lifestyle and adaptation of P. putida TJI51. Plant-associated Pseudomonas species 


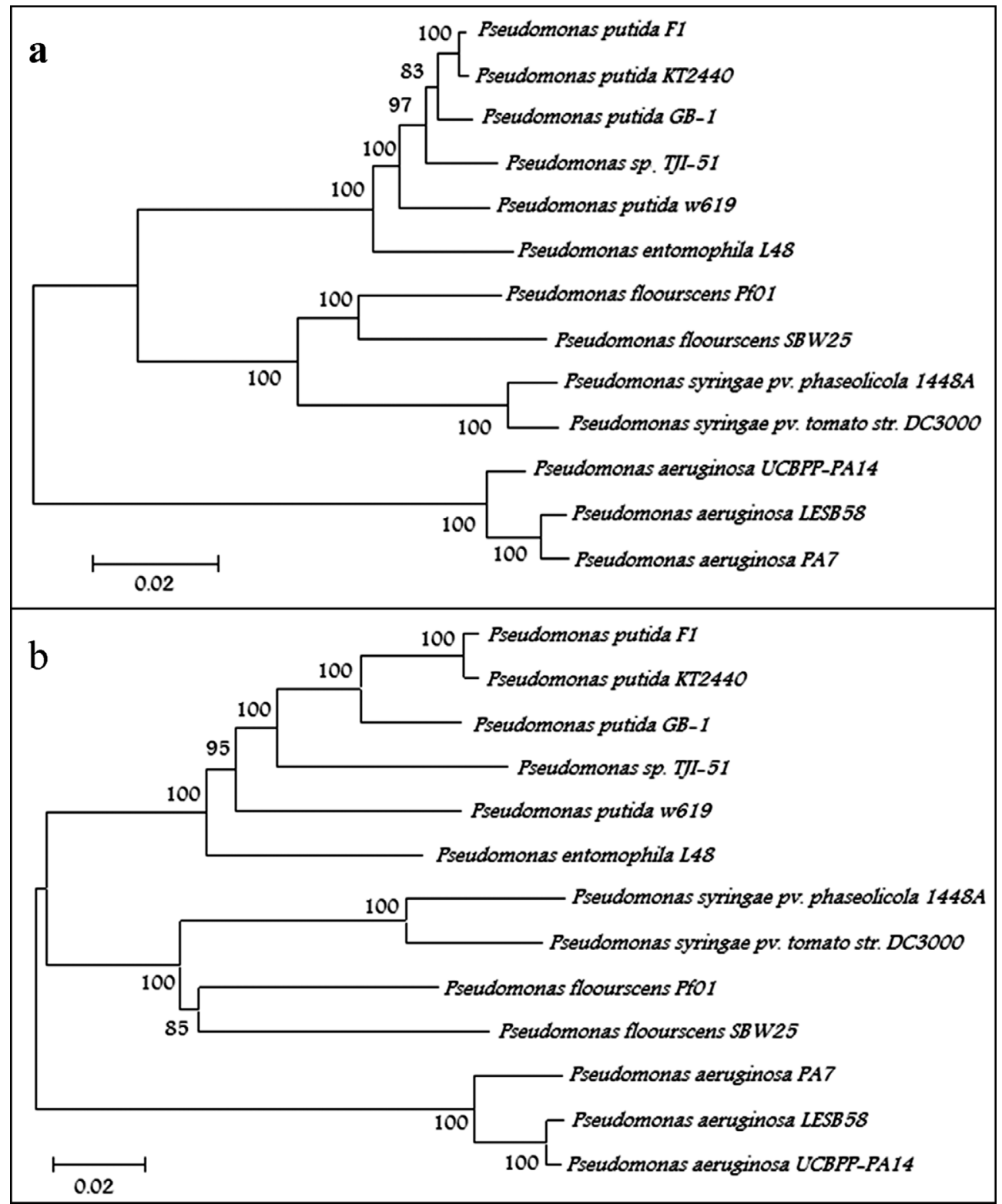

Figure 2 - Neighbor-Joining phylogenetic trees of $P$. putida TJI51 and other Pseudomonas species based on (A) concatenated sequence of five housekeeping genes ( $g y r B$, lepA, $r e c A$, $r e c G$ and $r p o D)$ and (B) concatenated amino acid sequence of ten conserved protein sequences. Bootstrap values are represented on the horizontal branches of the trees.

have rarely been reported from this part of the world. The genetic repository of $P$. putida TJI51 allowed comparative genomics and functional analysis with available Pseudomonas genomes for information related to the mode of association with plant tissues.

A sizeable number of genes were predicted to encode hypothetical proteins (i.e. 28\%). Analyses of newly sequenced bacterial genomes constantly reveal novelprotein coding genes; hence the size of the 'pan-genome' is increasing (Tettelinet al., 2008). BLAST searches in the NCBI non-redundant protein sequence database revealed 37 novel hypothetical proteins in $P$. putida TJI51 that have no database match (11 of these novel hypothetical proteins had $\geq 50$ amino acids, including hypothetical protein G1E_25761 which contained 1295 amino acids).

Analysis of the genome-wide alignment revealed 5-15 kb regions in P. putida TJ151 genome sequences that shared no detectable nucleotide sequence similarity with previously sequenced $P$. putida genomes. These regions were predicted to encode proteins involved in an array of biochemical pathways, including different oxidoreductases, glutathione S-transferase, isopenicillin N-synthase, xanthine permease, acetylornithine deacetylase, aldehyde dehydrogenase, benzoylformate decarboxylase, endoribonuclease, different $2 \mathrm{Fe}-2 \mathrm{~S}$ proteins, $\mathrm{ABC}$ transporters, extracellular solute-binding protein, xanthine dehydroge- 


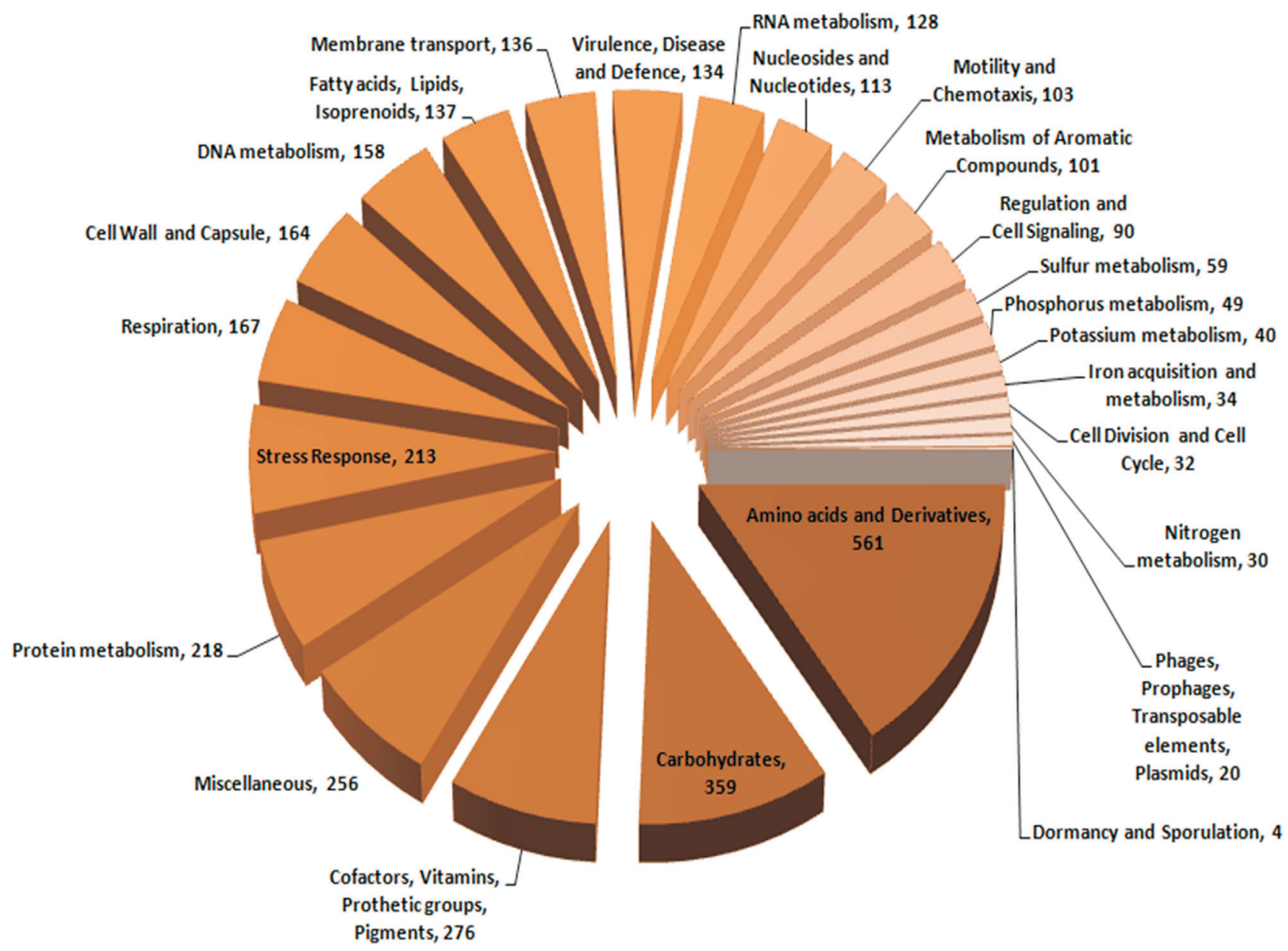

Figure 3 - Annotation of P. putida TJ151 genes by the NCBI Prokaryotic Genomes Automatic Annotation Pipeline (PGAAP) and their distribution according to different biochemical categories.

nase, hydroxyacylglutathione hydrolase, glucose dehydrogenase, uroporphyrinogen decarboxylase, and N-acetylglucosamine-binding protein. The P. putida TJ151 genome also appears to contain two plasmids (i.e. contig 20; AEWE02000020 and contig 77; AEWE02000077) and phage sequences (AEWE02000074). Contig 20 aligned with plasmid pGRT1 of the P. putida strain DOT-T1E, whereas Contig 77 aligned with plasmid sequences of several P. putida strains, including GB-1 and W619. Also among the $P$. putida TJ51-specific regions were genes predicted to encode resistance to heavy metals (contigs represented by GenBank entries AEWE02000041 and AEWE02000128), which may represent adaptations to treatment of the plant host environment with antimicrobial copper sulphate. The study generally augments the knowledge of the pan-genome of the ubiquitous and metabolically versatile species $P$. putida.

\section{ABC transporters in Pseudomonas putida TJI51}

The ATP-binding cassette $(\mathrm{ABC})$ transporters family of proteins are common in archaea, bacteria and eukaryotes. They facilitate active transport of an array of sub- strates, including ions, sugars, lipids, sterols, peptides, proteins, and drugs (Higgins, 1992). Bacterial ABC transporters typically are composed of three components; two integral membrane proteins, each having six transmembrane segments, two peripheral ATPase subunits, and a periplasmic substrate-binding protein. Usually, the genes for the three components form operons, as observed in many prokaryotic genomes.

KEGG analysis revealed $137 \mathrm{ABC}$ transporter system genes in the $P$. putida TJI51 genome sequence. We found a complete set of ATP transporter genes (i.e. integral membrane protein, ATPase and substrate-binding protein) for glycine/betaine/L-proline, different canonical amino acids, phosphate, sulfate, choline, urea, taurine, lipid, metal (i.e. $\mathrm{Fe}+3$, molybdate, nickel), oligopeptide/dipeptide, microcin $\mathrm{C}$, and spermidine/putrescine. Putrescine, or tetramethylenediamine (the precursor of spermidine), is a foulsmelling compound produced by the amino acid catabolism in living and dead organisms. Our analysis showed four distinct orthologous $\mathrm{ABC}$ transporter system gene sets for spermidine/putrescine in P. Putida TJI51. Hence, it appeared that $P$. putida TJI51 contains redundant sets of 
spermidine/putrescine $\mathrm{ABC}$ transporters. This observation is consistent with the fact that the isolate was obtained from dead mango bark tissues. We noted that the draft genome sequence of $P$. putida TJI51 did not contain complete operon sequences of these ATP transporter systems. More than one third of the 137 ATP transporter genes, i.e. 49 (36\%), were annotated as ATP transporter protein or ATP transporter-like protein. Hence, their substrate information could not be ascertained.

In $P$. putidaTJI51, the liv gene cluster $L I V$-I, specific for the branched-chain amino acid transport system, was comprised of a periplasmic binding protein LivK, two permease domains LivH and LivM, and two ATP-binding subunits LivF and LivG. Closely related orthologues of the liv gene cluster are found in other Pseudomonas species. This cluster is found functional in P. putida TJI51 and predicted to be involved in amino acid transport.

\section{TypeVI secretion system (T6SS) in Pseudomonas putida TJ151}

The type VI secretion system (T6SS) gene cluster is widespread among non-pathogenic and pathogenic gram negative bacteria (Boyer et al., 2009). This system enables the bacterial species to maintain pathogenic or symbiotic interaction with their eukaryotic host. The secretion systems facilitate the extracellular transport of proteins into the target eukaryotic cells without requiring hydrophobic amino-terminal sequences (Pukatzki et al., 2006). The
T6SS gene cluster comprises 14 core genes that vary in composition between different bacterial species (Bingle $e t$ al., 2008). Virulence associated secretion (vas) genes secreted by the T6SS are shown to be responsible for Vibrio cholera cytotoxicity towards Dictyostelium amoebae and mammalian J774 macrophages (Pukatzki et al., 2006). A survey showed that T6SS is present mostly in the nonpathogenic bacteria or symbionts, e.g. Myxococcus xanthus and P. putida (Bingle et al., 2008). However, more recently it has been reported to be involved in the virulence of Burkholderia mallei (Schell et al., 2007).

Bioinformatics analyses identified Vas genes to be highly conserved in Gram-negative bacteria. The comparison of the T6SS gene cluster in Pseudomonas putida TJI51 with other bacterial strains showed a closely related gene organization (Figure 4). The genes ImpG/VasA (numbered 3), Uncharacterized protein ImpC (numbered 2) and ImpH/VasB (numbered 4) were present at conserved relative positions, while the ImpI/VasC gene (numbered 7) was conserved in few strains.

\section{Association of Pseudomonas putida TJ151 with plants}

P. putida TJI51 was found to live in association with mango tree bark as an endophyte, and comparative genomics was used to identify the possible functions that are involved in the association of this bacterium with its host.

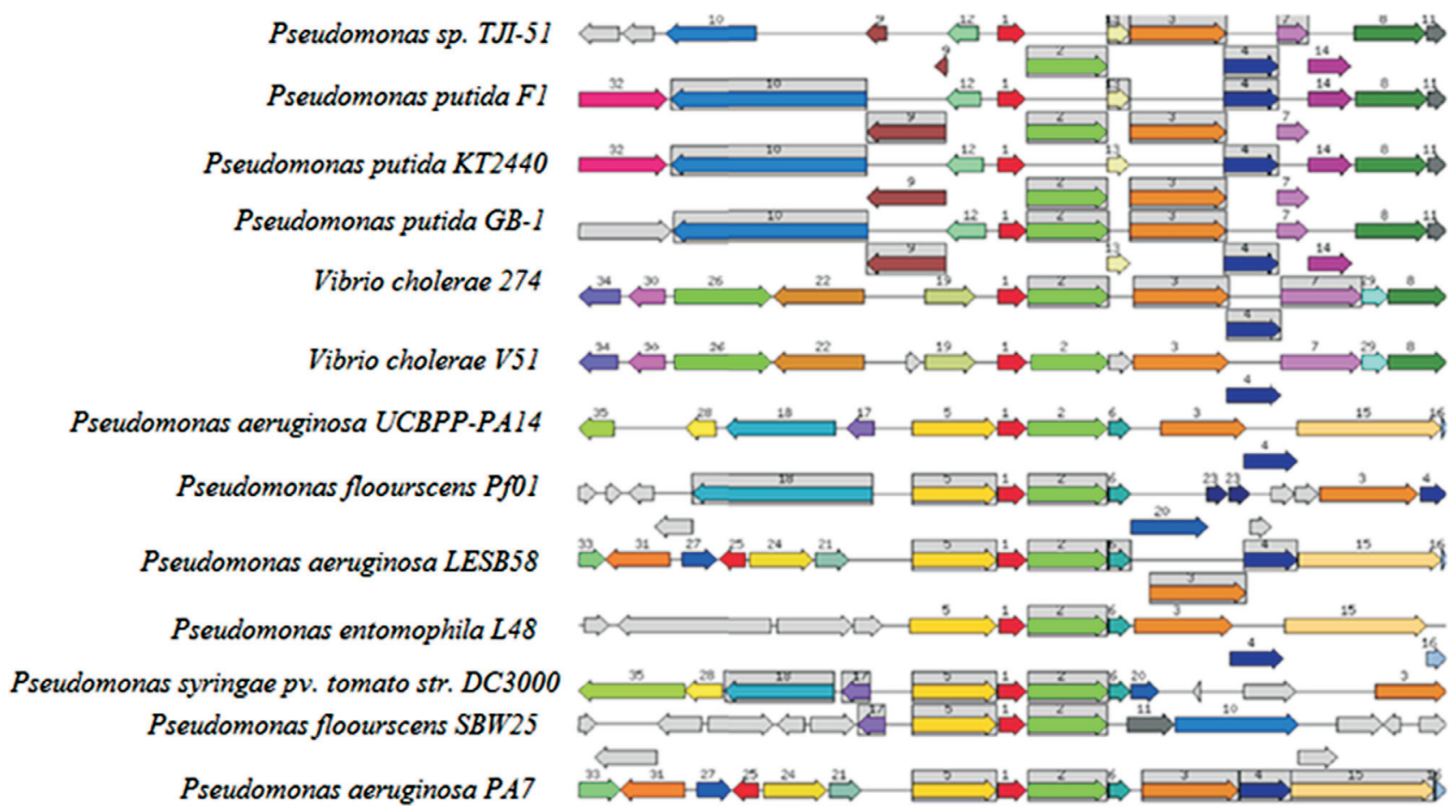

Figure 4 - Gene organization of Type VI secretion clusters. Homologous genes are grouped and shown with same number and color. Functionally coupled genes are highlighted in gray background boxes (ImpG/VasA (numbered 3, orange arrow), ImpC protein (numbered 2, green arrow), ImpH/VasB (numbered 4, blue arrow) and ImpI/VasC (numbered 7, purple arrow). 
KEGG analysis of the P. putida TJI51 genome revealed 26 genes involved in flagellar biosynthesis. All genes required for flagellar assembly were found present, including the $f l h B$ gene. It was reported that the impaired swimming capability of $P$. putida DOT-T1E (Segura et al., 2004) resulted from a mutation in the $f \operatorname{lh} B$ gene. The $P$. putida TJI51 flhB gene is $91 \%$ identical to that of P. Putida KT2440, which is known to be a good swimmer (Wu et al., 2011). These observations indicated a probable swimming capability of $P$. putida TJI51. Moreover, the KEGG analysis of the P. putida TJI51 genome revealed genes for all proteins involved in bacterial chemotaxis. Multiple genes for CheA $(\mathrm{n}=7)$ and $\mathrm{CheW}(\mathrm{n}=10)$ histidine kinases were found. Moreover, P. putida TJI51 also contains RbsB and DppA encoding genes involved in D-ribose and dipeptide chemotaxis in E. coli.

\section{Metabolism of secondary metabolites by Pseudomonas putida TJ151}

Many bacteria synthesize natural products with significant bioactivities, including antibiotics, anticancer agents, and other chemotherapeutics (Newman and Cragg, 2012). Microbial genome mining is a promising alternative for labor-intensive and time-consuming methods to identify and characterize bioactive secondary metabolites. The genome sequence analysis of $P$. putida TJI51 carried out by antiSMASH (Blin et al., 2013) and KEGG servers pointed out several genes putatively involved in the synthesis and catabolism of such metabolites. The antiSMASH (ANTIbiotics and Secondary Metabolites Analysis SHell) combines the automated identification of secondary metabolite gene clusters in genome sequences with a large collection of compound-specific analysis algorithms (Blin et al., 2013). AntiSMASH identified at least three non-ribosomal peptide synthetase gene clusters in P. putida TJI51 sequences. Non-ribosomal peptides produced by bacteria and fungi are a diverse family of secondary metabolites with a broad range of bioactivities (Schwarzeret al., 2003). Nonribosomal peptides are antibiotics, cytostatics and immunosuppressants, siderophores, or pigments. These peptides are synthesized by non-ribosomal peptide synthetases (NRPS) (Striekeret al., 2010). In bacteria, the NRPS genes for a certain peptide are usually organized in one operon in bacteria. The NRPS are organized in modules, where each module consists of several domains with defined functions. The domains of a complete NRPS include an adenylation domain (A-domain), thiolation and peptide carrier protein with attached phosphopantetheine (PCP domain), condensation domain for amide bond formation (C- domain), thioesterase domain for termination (TE domain), and an optional epimerization into D-amino acids domain (E-domain).

Two NRPS gene clusters found in P. Putida TJI51sequences were located in the following contigs. (1) Contig 131 (GenBank accession AEWE02000131) con- tained two sets of A-domain, PCP-domain and condensation domain. NRPS gene sequences in this contig were homologous to Burkholderia pseudomallei 1710b. (2) Contig82 (GenBank accession AEWE02000082) contained a novel set of A-domain, PCP-domain, condensation domain, along with an epimerization domain.

The genome analysis of $P$. putida TJ151by the KEGG server revealed catabolic pathways for the transformation of bioactive aromatic compounds, including L-tyrosine, Azathioprine/6-Mercaptoprine and Fluorouracil. Azathioprine is an immunosuppressive prodrug which is almost completely converted to 6-Mercaptoprine (Maltzman and Koretzky, 2003), whereas Fluorouracil is an anticancer drug. The KEGG analysis identified nine enzymes involved in biodegradation of these xenobiotics in the P. putida TJI51 genome.

\section{Acknowledgments}

This research was financially supported by the Higher Education Commission, Islamabad Pakistan.

\section{References}

Achouak W, Sutra L, Heulin T, Meyer JM, Fromin N, Degraeve S, Christen R and Gardan L (2000) Pseudomonas brassicacearum sp nov and Pseudomonas thivervalensis $s p$ nov, two root-associated bacteria from Brassica napus and Arabidopsis thaliana. Int J Syst Evol Microbiol 50:9-18.

Altschul SF, Gish W, Miller W, Meyers EW and Lipman DJ (1990) Basic local alignment search tool. J Mol Biol 215:403-410.

Blin K, Medema MH, Kazempour D, Fischbach MA, Breitling R, Takano E and Weber T (2013) antiSMASH 2.0 - An versatile platform for genome mining of secondary metabolite producers. Nucleic Acids Res 41:W204-W212.

Bingle LE, Bailey CM and Pallen MJ (2008) Type VI secretion, a beginner's guide. Curr Opin Microbiol 11:3-8.

Boyer F, Fichant G, Berthod J, Vandenbrouck Y and Attree I (2009) Dissecting the bacterial type VI secretion system by a genome wide in silico analysis: What can be learnt from available microbial genomic resources. BMC Genomics 10:e104.

Brown JR, Douady CJ, Italia MJ, Marshall WE and Stanhope MJ (2001) Universal trees based on large combined protein sequence data sets. Nat Genet 28:281-285.

Clarke PH (1982) The metabolic diversity of pseudomonads. Antonie Van Leeuwenhoek 48:105-130.

Dejongh M, Formsma K, Boillot P, Gould J, Rycenga M and Best A (2007) Toward the automated generation of genome-scale metabolic networks in the SEED. BMC Bioinformatics 8:e139.

Dejonghe W, Boon N, Seghers D, Top EM and Verstraete W (2001) Bioaugmentation of soils by increasing microbial richness: Missing links. Environ Microbiol 3:649-657.

Delcher AL, Kasif S, Fleischmann RD, Peterson J, White O and Salzberg SL (1999) Alignment of whole genomes. Nucleic Acids Res 27:2369-2376.

Ginard M, Lalucat J, Tummler B and Romling U (1997) Genome organization of Pseudomonas stutzeri and resulting taxo- 
nomic and evolutionary considerations. Int J Syst Bacteriol 47:132-143.

Higgins CF (1992) ABC transporters: From microorganisms to man. Annu Rev Cell Biol 8:67-113.

Kanehisa M, Araki M, Goto S, Hattori M, Hirakawa M, Itoh M, Katayama T, Kawashima S, Okuda S, Tokimatsu T, et al. (2008) KEGG for linking genomes to life and the environment. Nucleic Acids Res 36(suppl 1):D480-D484.

Khan IA, Khan A, Asif H, Jiskani MM, Mülbach H-P and Azim MK (2014) Isolation and 16S rDNA sequence analysis of bacteria from dieback affected mango orchards in southern Pakistan. Pak J Bot 46:1431-1435.

Larkin MA, Blackshields G, Brown NP, Chenna R, McGettigan PA, McWilliam H, Valentin F, Wallace IM, Wilm A, Lopez $\mathrm{R}$, et al. (2007) Clustal W and Clustal X version 2.0. Bioinformatics 23:2947-2948.

Liu R, Liu H, Feng H, Wang X, Zhang CX, Zhang KY and Lai R (2008) Pseudomonas duriflava sp nov, isolated from a desert soil. Int J Syst Evol Microbiol 58:1404-1408.

Madden TL, Tatusov RL and Zhang J (1996) Applications of Network BLAST Server. Methods Enzymol 266:131-141.

Maltzman JS and Koretzky GA (2003) Azathioprine: Old drug, new actions. J Clin Invest 111:1122-1124.

Manaia CM and Moore E (2002) Pseudomonas thermotolerans sp nov, a thermotolerant species of the genus Pseudomonas sensu strict. Int J Syst Evol Microbiol 52:2203-2209.

Markowitz VM, Chen IM, Palaniappan K, Chu K, Szeto E, Grechkin Y, Ratner A, Anderson I, Lykidis A, Mavromatis $\mathrm{K}$, et al. (2010) The integrated microbial genomes system; an expanding comparative analysis resource. Nucleic Acids Res 38:D382-D390.

Moon CD, Zhang XX, Matthijs S, Schafer M, Budzikiewicz H and Rainey PB (2008) Genomic, genetic and structural analysis of pyoverdine-mediated iron acquisition in the plant growth-promoting bacterium Pseudomonas fluorescens SBW25. BMC Microbiol 8:7-17.

Murray PR, Baron EJ, Jorgensen JH, Landry ML and Pfaller MA (2007) Manual of Clinical Microbiology. 9th edition. ASM Press, Washington DC, 2488 p.

Nelson KE, Weinel C and Paulsen IT (2002) Complete genome sequence and comparative analysis of the metabolically versatile Pseudomonas putida KT2440. Environ Microbiol 4:799-808.

Newman DJ and Cragg GM (2012) Natural products as sources of new drugs over the 30 years from 1981 to 2010. J Nat Prod 75:311-335.

Peix A, Ramírez-Bahena MH and Velázquez E (2009) Historical evolution and current status of the taxonomy of genus Pseudomonas. Infect Genet Evol 9:1132-1147.
Pukatzki S, Ma AT, Sturtevant D, Krastins B, Sarracino D, Nelson WC, Heidelberg JF and Mekalanos JJ (2006) Identification of a conserved bacterial protein secretion system in Vibrio cholerae using the Dictyostelium host model system. Proc Natl Acad Sci USA 103:1528-1533.

Rossello RA, García-Valde E, Lalucat J and Ursing J (1991) Genotypic and phenotypic diversity of Pseudomonas stutzeri. Syst Appl Microbiol 14:150-157.

Saitou N and Nei M (1987) The neighbor-joining method: A new method for reconstructing phylogenetic trees. Mol Biol Evol 4:406-425.

Santos SR and Ochman H (2004) Identification and phylogenetic sorting of bacterial lineages with universally conserved genes and proteins. Environ Microbiol 6:754-759.

Schell MA, Ulrich RL, Ribot WJ, Brueggemann EE, Hines HB, Chen D, Lipscomb L, Kim HS and Mrazek J (2007) Type VI secretion is a major virulence determinant in Burkholderia mallei. Mol Microbiol 64:1466-1485.

Schmidt KD, Tummler B and Romling U (1996) Comparative genome mapping of Pseudomonas aeruginosa $P A O$ with $P$. aeruginosa $\mathrm{C}$, which belongs to a major clone in cystic Fibrosis patients and aquatic habitats. J Bacteriol 178:85-93.

Schwarzer D, Finking R and Marahiel MA (2003) Nonribosomal peptides: From genes to products. Nat Prod Rep 20:275-287.

Segura A, Hurtado A, Dugue E and Ramos JL (2004) Transcriptional phase variation at the $f l h B$ gene of Pseudomonas putida DOT-T1E is involved in response to environmental changes and suggests the participation of the flagellar export system in solvent tolerance. J Bacteriol 186:1905-1909.

Spiers AJ, Buckling A and Rainey PB (2000) The causes of Pseudomonas diversity. Microbiology 146:2345-2350.

Strieker M, Tanovic A and Marahiel MA (2010) Nonribosomal peptide synthetases: Structures and dynamics. Curr Opin Struct Biol 20:234-240.

Tamura K, Dudley J, Nei M and Kumar S (2007) MEGA4: Molecular Evolutionary Genetics Analysis (MEGA) software version 4.0. Mol Biol Evol 24:1596-1599.

Tettelin H, Riley D, Cattuto C and Medini D (2008) Comparative genomics: The bacterial pan-genome. Curr Opin Microbiol 12:472-477.

Timmis KN (2002) Pseudomonas putida: A cosmopolitan opportunist per excellence. Environ Microbiol 4:779-781.

Wu X, Monchy S, Taghavi S, Zhu W, Ramos J and van der Lelie D (2011) Comparative genomics and functional analysis of niche-specfic adaptation in Pseudomonas putida. FEMS Microbiol Rev 35:299-323.

Associate Editor: Ana Tereza R. Vasconcelos

License information: This is an open-access article distributed under the terms of the Creative Commons Attribution License (type CC-BY), which permits unrestricted use, distribution and reproduction in any medium, provided the original article is properly cited. 